Cahiers $d u$ MONDE RUSSE

\section{Cahiers du monde russe}

Russie - Empire russe - Union soviétique et États indépendants

$58 / 4 \mid 2017$

Varia

\title{
Andreas Schönle, Andrei Zorin, Alexei Evstratov, éds., The Europeanized Elite in Russia, 1762-1825: Public Role and Subjective Self
}

\section{Константин Бугров еt Михаил Киселев}

\section{(2) OpenEdition}

Édition électronique

URL : http://journals.openedition.org/monderusse/10149

DOI : $10.4000 /$ monderusse. 10149

ISSN : $1777-5388$

Éditeur

Éditions de l'EHESS

Édition imprimée

Date de publication : 1 octobre 2017

Pagination : 685-694

ISBN : 978-2-7132-2698-4

ISSN : 1252-6576

Référence électronique

Константин Бугров и Михаил Киселев, «Andreas Schönle, Andrei Zorin, Alexei Evstratov, éds., The Europeanized Elite in Russia, 1762-1825: Public Role and Subjective Self», Cahiers du monde russe [Онлайн], 58/4 | 2017, Выложить онлайн 01 octobre 2017, Наводить справки в 06 janvier 2021 URL: http://journals.openedition.org/monderusse/10149; DOI: https://doi.org/10.4000/monderusse. 10149 
Andreas SCHÖNLE, Andrei ZORIN, Alexei EVSTRATOV, éds.

The Europeanized Elite in Russia, 1762-1825

Public Role and Subjective Self

DeKalb : Northern Illinois University Press, 2016, xii +371 p.

Российское дворянство имперского периода как объект изучения несколько последних десятилетий пользуется повышенным вниманием, что в немалой степени обусловлено совпадением стабильного интереса «западных» историков с приоритетами «от противного» постсоветской историографии, когда вместо изучения пролетариата и крестьянства исследователи обратились к темам, ранее не поощрявшимися из-за принципа «партийности». К настоящему времени написано немало работ по истории российского дворянства как дворянства, т.е. как социальной группы с имманентно присущими ей принципами развития. Вышедшая в 2017 г. коллективная монография под редакцией А. Шёнле, А. Зорина и А. Евстратова предлагает взглянуть на благородное сословие в России с другой точки зрения.

Авторов книги дворянство интересует, преждевсего, какевропеизированная элита. Соответственно, в центре внимания оказываются пути и результаты усвоения представителями российского дворянства (по преимуществу столичного) европейских идей ипрактикв XVIII-первой половине XIX вв. При этом, как показывают во введении А. Зорин и А. Шёнле, история российского дворянства в немалой степени представляет интерес как едва ли не самый первый - и наиболее удачный - пример формирования европеизированной элиты, который вполне можно соотнести с реставрацией Мэйдзи (Япония) и реформами Ататюрка (Турция). Правда, следует заметить, что сравнение петровских преобразований с японским опытом второй половины XIX в. и турецким первой половины XX в. до некоторой степени заслоняет тот факт, что европеизация дворянства в России произошло еще при господстве в Европе порядков Старого режима. Конечно, можно привести множество аргументов в поддержку тезиса о различии европейской и «московитской» культур. Однако между этими культурами существовали и важные типологические сходства, связанные с наличием сословного (в широком смысле слова) общества, на вершине которого стоял наследственный землевладельческий класс. Это в немалой степени и обусловило успех европеизации российской элиты. И уже с начала XIX в. постепенная гибель или трансформация порядков Старого режима в Европе при сохранении их внутреннего потенциала в России до крайности усложнила понимание феномена «русского европейца».

Отмечая, что историография при анализе европеизации обычно отдавала предпочтение трансферу идей, институтов и социальных норм, А. Зорин и А. Шёнле справедливо указывают, что существенно меньше внимания было уделено тому, каким образом элита адаптировала иностранные заимствования. В итоге, и сегодня довольно популярным остается подход, делящий общество имперской России на вестернизированную элиту и на необразованное простонародье. Отходя от подобного упрощенного 
видения, предполагающего едва ли не механическое усвоение элитой европейских новаций, авторы обращаются к анализу непростого процесса их интериоризации, который наиболее ярко проявлялся в трансформациях мировоззрения представителей дворянства.

Как отмечают А. Зорин и А. Шёнле, для изучения сложности ментального мира авторы сочли одним из наиболее эффективных подходов микроисторию. Соответственно, настоящая работа представляет, прежде всего, набор исследований кейсов-микроисторий. Последние, не будучи типичными в статистическом смысле, позволяют понять не только усваиваемую норму, но и то, как именно она адаптируется. При этом «они, как правило, демонстрировали конфликты между различными трендами и нормативными системами, вынуждая отдельных индивидов, а иногда и группы, прокладывать между ними свой маршрут» (р. 14). Именно стратегии и практики такого рода, согласно А. Зорину и А. Шёнле, и оказываются в центре внимания в этой книге, определяя подход авторов к материалу.

Кроме того, важным в методологическом отношении концептом, использованным в этой работе, является понятие «самосотворение» (self-fashioning), активно применяемое С. Гринблаттом ${ }^{1}$. Говоря о самосотворении для представителей элиты, А. Зорин и А. Шёнле исходят как из способности акторов делать «свободный» выбор, так и наличии границ для такого выбора. Соответственно, авторы этой коллективной работы исходили из посылки, что между социальной детерминацией и индивидуальной свободой существует спектр возможностей с различными уровнями давления и сопротивления. И, согласно А. Зорину и А. Шёнле, основное внимание при создании рецензируемой книги было уделено тому, что происходило посередине этих двух крайностей.

Первый раздел монографии, озаглавленный Internalizing Public Roles: Zealous Servicemen and Curious Noblemen, посвящен процессу европеизации до 1762 г. на примере трансформации представлений о принципах государственной службы и натурфилософии. И. Федюкин, продолжая исследование проблемы влияния представлений о человеческой природе на административные практики в России первой половины XVIII в. ${ }^{2}$, обращается в очерке From Passions to Ambitions: Human Nature and Governance from Peter I to the Emancipation of the Nobility к вопросу об изменениях принципов производства на вакансии в офицерские чины в 1710-х - начале 1740-х гг. По его мнению, Петр I, вполне в духе барочной политической культуры Московского царства конца XVII в., рассматривал подданных как персон, движимых предосудительными страстями (похоть, жадность и т.д.), с которыми следовало бороться. Так, согласно Петру, воздействие таких страстей в сфере кадровой политики приводило к тому, что продвигались на высокие должности не наиболее достойные, а наиболее услужливые и преданные начальникам. Соответственно, монарх искал способы, которые позволили бы ограничить влияние пристрастий высших администраторов на замещение открывавшихся в армии офицерских вакансий. Некоторыми из них стали принцип продвижения по старшинству и процедура выборов 
(«баллотировки») сослуживцами. После смерти императора генералитет стремился усилить свое влияние на кадровую политику и баллотировка была постепенно ликвидирована.

Однако, как показывает И. Федюкин, этот процесс сопровождался переосмыслением влияния страстей на службу. Амбиции и честолюбие стали теперь рассматриваться как основа «ревностной» службы, которые следовало всячески поощрять. Новая парадигма, с одной стороны, соответствовала основным трендам в европейских теориях управления и понимании дворянства, а с другой стороны позволяла представителям правящей элиты усилить собственное влияние и продвигать своих клиентов по службе. Все это подводило правящую элиту к идее ликвидации обязательной дворянской службы, что и произошло в 1762 г.

А. Иосад в очерке Curiosity, Utility, Pleasure: Official Discourses of Natural Philosophy and Their Alternatives in Russia in the Run-up to 1762 ставит вопрос об интеллектуальной и культурной автономии русского дворянства на примере развития официальных дискурсов натуральной философии и их альтернатив в России до 1762 г. Он показывает, как к середине XVIII в. на смену господствовавшей в натурфилософии с петровских времен официозной «культуре куриозности» пришел подход, сводивший суть природы к математическим описаниям или иерархической таксономии каталога. Если первая была представлена Кунсткамерой, то вторая - Академией наук. Далее, рассмотрев восприятие тремя персонами - М.В. Ломоносовым, графом И. Г. Чернышевым и В.А. Нащокиным - трагической гибели профессора Г.В. Рихмана в 1753 г. во время опытов, автор приходит к выводу о том, что, несмотря на смену официальной модели взаимодействия с природой, петровская «культура куриозности» продолжила свое развитие в дворянской среде. Следовательно, российское дворянство интенсивно формировало собственные представления о науке, которые хотя и были связаны с официальными академическими дискурсами, однако могли и конфликтовать с ними.

Второй раздел книги The Court and the Family. Cuckolded Husbands and Lonely Wives открывается работой А. Евстратова Dramatic Conflicts and Social Performance at the Russian Court in 1760es: A Sociocultural Perspective on Marital Infidelity, где рассматривается знаменитая история о разводе графа А.С. Строганова и графини А.М. Строгановой (урожденной Воронцовой), наделавшая много шума в придворных кругах 1760-х гг. Евстратов анализирует интересный документ - список вымышленных сатирических «пьес» и их «авторов», ходивший при дворе - в контексте разнообразных свидетельств и воспоминаний о публичном отражении конфликта супругов Строгановых. Это позволяет исследователю утверждать, что Строганов старался разными путями сформировать свой образ «на публику»: к хорошо известному по европейским пьесам образу обманутого, но счастливого рогоносца Строганов добавил имидж русского Жоржа Дандена, мольеровского персонажа богатого крестьянина, пытающегося (безуспешно) с помощью выгодной женитьбы войти в круг надменных аристократов. 
Статья безвременно ушедшей М. Мappeзе Performing Womanhood in Eighteenth-Century Russia. Cultural Identity in the Letters of Ekaterina Rumiantseva and Dar 'ia Saltykova основана на ином методе. Она содержит детальный анализ переписки представительниц аристократических семей XVIII столетия, организованный вокруг крупных тематических блоков: семейных отношений, «публичных» событий и «культурного потребления». Графини Е.М. Румянцева и Д.П.Салтыкова были яркими представительницами высшего слоя дворянской элиты, оставшимися по причине отъезда мужей видных военных деятелей - на службу полновластными хозяйками огромных имений. Отсутствие мужей стало причиной интенсивного обмена письмами, и письма эти, по справедливому замечанию М. Маррезе, «занимают уникальное место в среде женских литературных произведений (artifacts)» российского XVIII столетия (р. 91). Вывод М. Маррезе не только противоречит выводам Ю.М. Лотмана, но и - в определенной степени - выводам А. Евстратова: предполагаемая двойственная идентичность российских аристократок вообще никак не проявляла себя в переписке, не содержат их письма и отсылок к литературным моделям.

Раздел The Domestic Economy: Between Ostentation and Rationalization посвящен домашней экономике дворянской элиты. Е. Корчмина, автор очерка под названием The Practice of Personal Finance and the Problem of Debt among the Noble Elite in Eighteenth-Century Russia, обращается к проблеме долгов дворянской элиты в России XVIII в. и показывает, как представители высшего дворянства пытались приспособиться к менявшейся экономической среде при помощи все более совершенных приемов подсчета расходов и доходов, в том числе заимствовавшихся из европейской финансовой культуры. Впрочем, несмотря на усилия такого рода, во второй половине XVIII в. уровень задолженности дворянской элиты вырос. Не в последнюю очередь это было связано со спецификой адаптации европейских новаций. Так, в отличие от Европы, в России едва ли не до отмены крепостного права богатство дворянина определялось не его годовым доходом, а числом душ, которыми он владел. По мнению Е. Корчминой, дворянин, рассчитывая предельную сумму долга, мог соотносить ее не с годовым доходом, а со своим имуществом, которое можно было продать в случае необходимости.

Правда, здесь возникает вопрос: на какие же средства должен был бы жить аристократ, лишившийся имущества?Какпредставляется, анализ соотношения доходов и расходов, равно как и подсчет годового дохода, не позволит получить полноценного ответа на такой вопрос без учета социального контекста. Как полагают А. Зорин и А. Шёнле, стремление к экономической рационализации с целью избежать роста задолженности вступало в конфликт с привычками к престижному потреблению европейских товаров; подобную ситуацию можно рассматривать как свидетельство внутренней противоречивости проекта европеизации (р. 321). Однако высокое положение при дворе, предполагавшее большие издержки, одновременно предполагало и возможность обращения к государственным ресурсам для улучшения собственных финансов. 
Так, Воронцовы, о которых идет речь в очерке Е. Корчминой, в ходе коррупционной приватизации в царствование Елизаветы Петровны получили Верх-Исетский завод под Екатеринбургом за 35712 рублей, а затем, «чтобы избежать долгу», продали его за 200000 рублей. А накопивший к 1794 г. более полумиллиона рублей долгов граф И.Г. Чернышев не постеснялся обратиться к Екатерине II с просьбой о пожаловании староства в 5000 душ в Полоцкой губернии ${ }^{3}$. В связи с этим актуальными остаются заключения С.Я. Борового о том, что кредитно-финансовая политика правительства второй половины XVIII - первой половины XIX вв. проводилась в режиме наибольшего благоприятствования крупнейшим «душевладельцам» ${ }^{4}$ Возможно, все это говорило не только о противоречивости европеизации как таковой, но и о том, что заимствованный с Запада интеллектуальный инструментарий, попав в новый социальный контекст, начинал адаптироваться к этим реалиям с их специфическими правилами. Рациональные бухгалтерские приемы должны были не ликвидировать престижное потребление российской дворянской элиты, а, скорее, упорядочить его с учетом финансовых милостей суверена, заинтересованного как в поддержании блеска своего двора, так и благосостояния благородного сословия.

В очерке Self-Fashioning, Estate Design, and Agricultural Improvement: I. I. Bariatinskii's Enlightened Reforms of the Country Living А. Шёнле ставит целью пересмотр исследовательского подхода М. Конфино, согласно которому сельская жизнь как дворянства, так и крестьянства была детерминирована статичными структурами аграрного строя. Обращаясь к деятельности князя И.И. Барятинского, в юности - поклонника Французской революции, а впоследствии - богатого душевладельца, Шёнле убедительно доказывает, что сельские усадьбы, эти «дворянские гнезда», предоставляли элите прекрасную возможность для разнообразных экспериментов, связанных с воплощением в реальность европеизированного стиля жизни: двигателем для этого выступали не только сугубо экономические, но и эстетические соображения, а также требования престижа. Кроме того, Барятинский считал хозяйственное преобразование своего имения службой на благо страны (р. 137) и инструментом социального дисциплинирования подвластных крестьян ради их же счастья (р. 143). Это, впрочем, вовсе не предполагало значимых изменений в сфере политики и социальных отношений, включая крепостное право. А европеизированная риторика заботы о крестьянах становилась еще одним источником легитимации крепостного права: европейские взгляды и риторика общего блага вовсе не противоречили практическому осуществлению власти Барятинского над своими крестьянами (здесь, наряду с критикой М. Конфино, А. Шёнле оспаривает и известный тезис Ю. М. Лотмана).

Раздел Officers off the Battlefield: Managers and Thinkers открывается очерком С. Андриайнена Warriors in Peace: The Everyday Life of Russian Officers at the Beginning of the Nineteenth Century. Несмотря на многообещающее название, речь в очерке идет о довольно узкой проблеме: служебных хлопотах 
гвардейских офицеров, особенно Конного полка, связанных преимущественно с материальным обеспечением вверенных им частей. Бюрократия оказывала на этих командиров подразделений давление, стремясь с помощью жесткой регламентации службы искоренить злоупотребления и сократить расходы. Но поскольку система снабжения оставалась фрагментированной, офицерам, пусть и рисковавшим быть наказанными за нарушение официальных предписаний, представлялся широкий спектр возможностей для демонстрации личной ответственности и принятия самостоятельных решений.

М. Велижев, автор очерка The Political Language of the Europeanized Military Elite in the Early Nineteenth Century: The Unpublished Diary and Letters of Vasilii Viazemskii, анализирует политический язык «европеизированной военной элиты» начала XIX в. на примере дневника и писем генерал-майора В. В. Вяземского. Правда, принадлежность последнего к особому кругу военной элиты проявлялась главным образом в выборе тем для размышлений и вряд ли накладывал отпечаток на его политический язык. Отметив некоторую противоречивость рассуждений Вяземского, автор делает вывод о том, что европеизация - по крайней мере, в идейной сфере - заключалась не в заимствовании готовых и логически последовательных ответов на вопросы, возникавших в ходе культурных, военных или политических контактов. Скорее, она состояла в овладении искусством задавать подобные вопросы, приводя к генерации противоречий, апорий и к разрыву между категориями и явлениями, соотносимыми в разных социокультурных контекстах. Именно образование таких смысловых разрывов, согласно М. Велижеву, было сущностью процесса европеизации в России, а ее конституирующими атрибутами оказывались напряженность и противоречия, возникающие в этом процессе.

Следующий раздел посвящен институтам «социабельности», возникшим в ходе европеизации в Москве и представлявшим альтернативу придворной сфере Санкт-Петербурга. Его открывает очерк А. Зорина The Emotional Culture of Moscow Rosicrucians: An Experiment in Alternative Europeanization об эмоциональной культуре московских розенкрейцеров, где рассматриваются их способы конструирования внутреннего мира, выстраивания отношений друг с другом и властями, а также роль секретности в организации сложного комплекса взаимоотношений 5 .

М. Велижев в очерке The Moscow English Club and the Public Sphere in Early Nighteenth-Century Russia рассматривает проблему функционирования институтов публичной сферы в России первой половины XIX в. на примере Московского Английского клуба. Он отмечает, что в Англии и США развитие институтов публичной сферы, включая клубы, было связано с процессами урбанизации, а публичная сфера играла роль посредника между старыми и новыми городскими элитами. В то же время, анализ истории Московского Английского клуба в контексте урбанизации показывает: клуб этот был крепостью старого московского дворянства, своеобразной корпоративной институцией благородного сословия Москвы. Можно сказать, что очерк М. Велижева ярко демонстрирует, как европейские институции, помещаемые 
в иной социальный, политический и экономический контексты, могли в логике своего развития весьма далеко уйти от заимствованного образца.

М. Велижев делает чрезвычайно интересное (и парадоксальное) утверждение, что в России в первой половине XIX в. все же существовало пространство, которое обладало такими характеристиками хорошо функционирующего публичного института, как динамичное внутреннее развитие, европейский уровень культуры и образования и высокая степень политической рефлексии. Пространством этим была армия (р. 234). Такое положение дел устраивало императора (по крайней мере, Александра I), в то время как типичные городские формы публичной сферы (пресса, городские клубы и общества, масонские ложи) рассматривались как крайне подозрительные институции. На наш взгляд, столь смелое утверждение нуждается в дополнительном обосновании, и вовсе не из-за памятного обещания грибоедовского Скалозуба насчет Вольтера и фельдфебеля. Можно ли считать армию разновидностью публичной сферы? Были ли политические интересы офицеров продуктом специфически «армейского» окружения? ${ }^{6}$ Думается, что поиск ответов на эти вопросы может стать в ближайшие годы чрезвычайно интересным исследовательским направлением.

В разделе Experiencing the Other: Foreigners and Coachmen рассматриваются вопросы отношений между элитой и другими социальными группами; как отмечено во введении к этому разделу, экипаж, в котором «ехали» члены элиты, должен был кто-то обслуживать - например, ямщик, ставший для русской литературы того времени значимой фигурой. Для анализа в качестве примеров авторами рассматриваемой книги были выбраны такие группы, как иностранцы (кейс национальных различий) и, действительно, ямщики (кейс социального неравенства).

В очерке А. Евстратова Russian Prince vs. "German Swine”: Public Slap in the Face, Émigrés, and Local Elites in St. Petersburg at the Time of the French Revolution рассматривается история о дуэли между князем Н.Г. Щербатовым и французским эмигрантом, сыном саксонского принца-регента Ж. де Саксом. История, начавшаяся в 1795 г. взаимным оскорблением и скандалом в Петергофе, получила драматическую развязку в 1802 г., когда на дуэли, отложенной на семь лет и состоявшейся в австрийском Теплице, Щербатов застрелил-таки своего обидчика. А. Евстратов, анализируя различные мемуарные свидетельства и анекдоты об этой поистине легендарной дуэли, убедительно демонстрирует, как переплетаются в элитной среде аристократический и национальный дискурсы.

Д. Рандольф посвятил очерк Between Friends, a Coachman: Enlightenment Encounters Empire in Russia's Eighteenth Century восприятию своеобразной группы ямщиков в среде европеизированной дворянской элиты. Ведь путешествующих дворян кому-то нужно было перемещать с места на место, а также доставлять их корреспонденцию... Почтовая и транспортная инфраструктура, с которой сталкивались члены элиты, была, по замечанию Д. Рандольфа, не просто посредником между культурами, 
но и самостоятельным культурным пространством. Перемещения в пространстве предполагали для членов элиты столкновение с этой культурой, многочисленные следы такого столкновения разбросаны по страницам русской литературы - от А.Н. Радищева и А.С. Пушкина до «Тарантаса» В.А. Соллогуба.

Заключительный раздел сборника носит название The Radical Bifurcation: The Way to Europe and to the Convent. Первый из этих маршрутов исследован в очерке А. Шёнле The Instability of Time and Plurality of Selves at Court and in Society. Значимость этой работы весьма велика: автор анализирует вопрос о том, как изменчивость положения придворного, все время вынужденного находиться в водовороте событий, не поддающихся контролю с его стороны (специфика этого положения осознавалась российской элитой как минимум со времен князя А. Д. Кантемира, который в «Сатире II» упоминал «камергера» Клита, держащего язык за зубами и старательно охотящегося за счастьем в приемных могущественных вельмож), привела к концу XVIII в. к складыванию многомерного «я» (self) высшего слоя российского дворянства. Стратегии, нацеленные на минимизацию устрашающей придворной нестабильности, могли быть разнообразными. Иногда это был отказ от тягот придворной жизни, бегство к сельской размеренности и добровольная изоляция в поместье. Однако, как показывает А. Шёнле, этот выбор не был легким, поскольку высшее дворянство зависело от двора как источника материальных благ. С середины XVIII в. формируется иной дискурс, в котором нестабильность придворной жизни оказалась подчинена общему вектору петровской модернизации, в которой государи - наследники Петра и их верные помощники-дворяне работали бок о бок; патриотизм, ориентированный на фигуру монарха-демиурга позволял игнорировать трудности и тяготы придворной нестабильности (р. 290-291). Крайним проявлением этой проблемы оказался случай Н.И. Тургенева, рассмотренный в заключительной части очерка: его «абстрактная привязанность к России и неспособность примириться с необходимостью проживать в ней иллюстрируют увеличивающийся разрыв между рефлективными, политическими и персональными (relational) параметрами идентичности» (р. 297).

Семейство Тургеневых сопровождает читателя и в очерке А. Зорина Sentimental Piety and Orthodox Pietism: The Case of Nun Serafima. В центре внимания исследователя - «история образованной, европеизированной московской женщины, которая проложила свой путь между традиционной православной культурой и эмоциональной и духовной культурой, превалировавшей среди студентов Университетского благородного пансиона, их друзей и родственников». Если центральная фигура очерка - это B.М. Соковнина (схиигумения Серафима), ушедшая в монастырь против воли своей матери, то вот «друзья и родственники», которым А. Зорин уделяет не меньше внимания - это в первую очередь братья Н.И. Тургенева, Александр (который был влюблен в В.М. Соковнину) и Андрей. И если «Автобиография» Серафимы представляет ее жизненную историю в жанре, напоминающем 
об агиографической литературе, то изложение этих же событий в письмах и дневнике Андрея Тургенева превращает житие в «сентиментальную историю» (р. 312). В конечном счете, история Серафимы (Соковниной) послужила, возможно, источником вдохновения для еще одного Тургенева - Ивана Андреевича, став прообразом Лизы Калитиной, главной героини романа «Дворянское гнездо».

Согласно заключению, написанному А. Зориным и А. Шёнле, полученные коллективом авторов результаты позволяют говорить, что для российского дворянства европеизация оказалось отнюдь не внешним принятием набора поведенческих кодов, как это предполагается концепцией театрализации дворянского поведения Ю.М. Лотмана. По их мнению, европеизация предполагала также процесс интериоризации, который, будучи изначально поощряем правителями страны, постепенно приводил к внутренней перестройке структур чувствования и мышления элиты. Другое ключевое суждение, которое можно вынести по прочтении основной части этой коллективной монографии, состоит в том, что сценарии европеизации были весьма разнообразны и не предполагали простых способов воплощения. Название одного из разделов книги позволяет образно сформулировать этот вывод: одна и та же дорога вела представителей элиты и в Европу, и в монастырь. Но этими двумя направлениями карта маршрутов вовсе не исчерпывалась: дороги эти могли вести и в поместье, и к дуэльному барьеру, и в Английский клуб. Общим же было то, что все эти маршруты вели путешествующих путями самосотворения, исключая возможность говорить о европеизации как о движении к единому, понятному и внеположенному образцу. При этом отмеченная множественность сценариев выводит исследователей к проблеме их совместимости. По мнению А. Зорина и А. Шёнле, со временем диссонансы между ними могли нарастать, что проявилось в «нормальном исключительном» казусе П.Я. Чаадаева. Это, впрочем, не означает справедливости тезиса М. Раева о предполагаемом «отчуждении», которое якобы испытывало дворянство. Напротив, дворянская элита продолжала сохранять свои привилегии, равно как и нести ответственность за страну - а это, в свою очередь, препятствовало чувствам маргинализации и отстраненности от вопросов управления государством.

В завершение следует сказать, что рецензируемая монография открывает интересные перспективы в осмыслении дворянской культуры России имперской эпохи, а анализ противоречий и коллизий российской европеизации, на изучении которых делают акцент авторы книги, сохраняет актуальность и сегодня.

1 -В 1999 г. при публикации избранных фрагментов из ключевой книги С. Гринблатта, Г. Дашевский перевел self-fashioning как «формирование “я”». См.: С. Гринблатт, Формирование «я» в эпоху Ренессанса: от Мора до Шекспира (главы из книги) / пер. Г. Дашевского, Новое литературное обозрение, 1999, № 35.

2 - См.: I. Fedyukin, «An Infinite Variety of Inclinations and Appetites: Génie and Governance in Post-Petrine Russia», Kritika: Explorations in Russian and Eurasian History, 
2010, Vol. 11, No. 4; И.И. Федюкин, «“Честь к делу ум и охоту раждает”: реформа дворянской службы и теоретические основы сословной политики в 1730-е гг.», Гиштории российские, или Опыты и разыскания к юбилею Александра Борисовича Каменского, М., 2014.

3 -Н.И. Павленко, История металлургии в России XVIII века: Заводы и заводовладельиь, М., 1962, С. 385.

4 -С.Я. Боровой, «Кредитная политика царизма в условиях разложения крепостничества», Bопросы истории, 1954, № 2, С. 129-135. См. также: В.В. Морозан, История банковского дела в России (вторая половина XVIII-первая половина ХІХ в.), СПб., 2004, С. 76-102.

5 - См. также: А.Л. Зорин, Появление героя: Из истории русской эмоциональной культуры конца XVIII - начала XIX века, М., 2016, С. 102-138.

6 - М. Велижев, например, ссылается на длительный опыт пребывания офицеров императорской армии за рубежом в ходе войн 1812-1814 гг., предположительно повлиявший на рост их «политизированности». Но примерно столько же времени русские офицеры провели в Европе и в ходе Семилетней войны 1757-1763 гг,, а до этого в 1735-1736 гг. российский экспедиционный корпус находился на территории Германии; стоит отметить и тот факт, что офицерство императорской армии было на протяжении XVIII в. весьма космополитичным из-за притока иностранных специалистов, лишь усиленного на рубеже XVIII-XIX вв. эмиграцией из охваченной революционными войнами Европы.

\section{Константин Бугров}

Институт истории и археологии Уральского отделения Российской академии наук

Михаил Киселев

Институт истории и археологии Уральского отделения Российской академии наук 